INFANTS WITH UNILATERAL HEARING LOSS

\begin{abstract}
Background: Parents of infants identified with unilateral hearing loss (UHL) make decisions about managing their infant's hearing loss based on limited evidence and before knowing whether their infant will require additional support.

Objectives: The decision-making processes of parents and clinicians regarding the management of UHL following newborn hearing screening were examined.

Procedure: Two convenience samples were recruited: 15 parents of children with permanent UHL aged under 4 years, and 14 clinicians. Applied thematic analysis of the semi-structured interviews elicited insight into the complexities surrounding decision-making from a parent and clinician perspective.
\end{abstract}

Results: Three main themes captured the decision-making process: motivation for decisionmaking, limited evidence creates uncertainty, and available evidence builds certainty. The diverse experiences and opinions of parents and clinicians highlight the complexity of decision-making when there are contested opinions and no clear best management option. Conclusions: The choices parents make about the management of their child's UHL can have lifelong implications for their child. Many questions need answering before parents can effectively evaluate the short- and long-term consequences of their options and whether the advantages outweigh the disadvantages in the long-term. This uncertainty is challenging for professionals and parents and risks cognitive biases influencing clinical and parental decision-making.

\title{
Keywords
}

Unilateral hearing loss

Single-sided deafness

Infants

Decision making

Parent

Clinicians 
INFANTS WITH UNILATERAL HEARING LOSS

\section{Decision-Making Following Identification of an Infant's Unilateral Hearing \\ Loss: Parent and Professional Perspectives}

\section{Introduction}

When an infant is identified with hearing loss through newborn hearing screening, parents are required to make decisions that have the potential to have lifelong consequences for the child. When universal newborn hearing screening was introduced in Australia in 2001, parents were given few options to manage their infant's unilateral hearing loss (UHL) ${ }^{1}$ other than regular monitoring of the child's hearing. This has changed in recent years with the same array of options available to children with UHL as children with bilateral hearing loss [1]. However, the evidence for outcomes and interventions in the UHL population has not kept pace with the changing expectations of parents and little is known about how parents and clinicians approach the decision-making process in this shifting environment.

It has been over three decades since Bess and Tharpe [2] first signalled that UHL could have adverse consequences for children. In their study, 35\% of the 60 children who had normal hearing thresholds in one ear and some degree of hearing loss in the other had failed at least one grade at school, and a further $13 \%$ required some additional support in the classroom. The past decade has seen many published articles on UHL in both children and adults, although high-quality evidence on outcomes and interventions remains scarce [3].

Recent systematic reviews have examined a number of topics related to children with UHL, including auditory outcomes of conventional hearing aids, bone-conduction devices, remote microphone systems and contralateral routing of signal aids [4], speech and language outcomes [5], the impact of early onset UHL on children [3], bone-conduction devices [6],

\footnotetext{
${ }^{1}$ A child is considered to have a unilateral hearing loss (UHL) if they have hearing thresholds in the normal range in one ear and any degree of hearing loss in the other. Children with hearing thresholds in the normal range in one ear and a hearing loss that could not be helped with acoustic amplification are described as having single-sided deafness.
} 
INFANTS WITH UNILATERAL HEARING LOSS

cochlear implantation [7], intelligence quotient scores [8], and parental decision-making [9].

These systematic reviews indicate that, despite the increased number of publications on children with UHL, it is difficult to draw any firm conclusions regarding the outcomes or options open to them due to the limited availability of quality studies. The consensus practice parameter for the audiological assessment and management of children with UHL has identified a number of key areas where consistency in study design and reporting could address the current knowledge gaps about outcomes and management options for children identified with UHL [10].

This consensus practice paper [10] has provided guidance on management and rehabilitative options for babies identified with UHL. Four areas for the management of hearing loss were discussed - audiological monitoring, developmental monitoring, early childhood intervention services, and hearing assistive technology management. The consensus paper endorsed the consideration of conventional hearing aids, bone-conduction devices, remote microphone systems, contralateral routing of signal aids, and cochlear implantation "in the context of the child's and family's needs and desires" (p.5). The uncertainty about which children are at risk of poorer outcomes, and the contested best practice options for the management of UHL in children, makes decision-making about appropriate management of UHL in infants difficult for both parents and practitioners [11].

\subsection{UHL and the Australian context.}

Australia has six states and two mainland territories, with newborn hearing screening the responsibility of the state and territory governments (see Figure 1). While the National Framework for Neonatal Hearing Screening provides high-level guidance for the implementation of newborn hearing screening across Australia, each state or territory has different protocols and procedures for implementing this [12]. All children diagnosed with a permanent hearing loss, including those with UHL, have access to the Australian 
INFANTS WITH UNILATERAL HEARING LOSS

Government Hearing Services Program delivered through Hearing Australia (a

Commonwealth Government statutory authority) until 26 years of age. This governmentfunded program includes ongoing audiological assessment and the provision of hearing aids, cochlear implant upgrades, and other assistive listening devices. In November 2017, children with UHL became eligible for the Australian Government-funded National Disability Insurance Scheme and, as a result, were provided with free access to early childhood intervention services [13].

\section{Insert Figure 1 about here}

\subsection{Decision-making in clinical settings}

Evidence-based medical research highlights the need for patients to make informed decisions by having access to quality, evidence-based information and considering their preferences before an intervention is implemented [14]. Patients are encouraged to be involved in the decision-making process and provided with greater autonomy to make decisions that best suit their particular condition, circumstances and preferences [15]. In healthcare, however, there is often no best option for an intervention or treatment, generally due to insufficient evidence to indicate the superiority of one option over another [16]. Uncertainty can be challenging for both clinicians and patients. Clinicians are required to expend more time and effort exploring counterfactual situations with patients, and patients need to acknowledge that there might be no clear answer [16]. Shared decision-making, which is now viewed as the standard for good clinical care in many countries $[17,18]$, is particularly well-suited to these situations, but there is evidence that health professionals struggle to incorporate this process of deliberation into their day-to-day clinical practice and seldom discuss the expectations and concerns of their patients [16, 19]. This is despite research over the past decade specifying ways of providing balanced information to patients 
INFANTS WITH UNILATERAL HEARING LOSS

to promote informed choice and allowing the decision-maker to process and act upon the information without being unduly influenced [20].

\subsection{Parent decision making for UHL management}

A recent systematic review of the literature highlighted the paucity of research on the information and decision support needs of parents of children with UHL [9]. Of the 37 papers reviewed, only 1 examined parental decision-making for a child with UHL [21] and found that many of the 23 parents or caregivers surveyed experienced decisional conflict when deciding whether to proceed with bone-anchored hearing device surgery for their child. The most common reasons for refusing surgery were aesthetic concerns and perceptions that surgery would not significantly improve the child's quality of life. A qualitative study of parents of children with minimal hearing loss by Fitzpatrick et al. [22], which included 11 children with unilateral hearing loss, found that confusion and uncertainty dominated decisions about amplification, with mixed messages from different professionals about the effectiveness of device use, particularly in infants. More recently, Hussain et al. [23] interviewed the parents of children with $\operatorname{UHL}(N=21)$ to explore their decision-making regarding their child's habilitation needs. They found that parents searched for a "new normal" while struggling to weigh up the conflicting information and recommendations of clinical and support networks.

There is also little information on decision-making from a clinician perspective. Fitzpatrick et al. [24] investigated the clinical decision-making of 64 audiologists regarding amplification in six scenarios involving minimal or unilateral hearing loss. The results of the survey found the majority of audiologists would recommend amplification for children with UHL in these scenarios. A survey of 52 paediatric audiologists at Hearing Australia in 2014 showed greater variability, with two-thirds of the respondents sometimes recommending a listening device for infants with UHL, while a third always recommended amplification [11]. 
INFANTS WITH UNILATERAL HEARING LOSS

The international panel of experts on children with UHL has provided consensus-based discussion points for audiologists when counselling parents about the management of their child's unilateral hearing loss [10]. There remains, however, a dearth of published reports on the experiences and perspectives of parents or clinicians regarding parental decision-making following the identification of UHL in infants. The current study addressed this gap in knowledge by exploring the decision-making process following diagnostic audiology from both parent and professional perspectives.

\subsection{Current study}

The aims for the current study were to understand (a) the decision-making processes of parents when making decisions about the management of their infant's UHL, and (b) the clinician's perspective on decision support needs of parents regarding the management of their infant's UHL. To address these issues, we interviewed parents of children with UHL and clinicians who assist them with their decision-making.

\section{Method}

\subsection{Participants}

We interviewed 15 parents of children under 4 years of age who were identified with a permanent UHL through newborn hearing screening, and 14 clinicians working with families following the identification of their infant's hearing loss. Tables 1 to 3 report the demographic details for parents, the children with UHL, and the clinicians, respectively.

\section{Insert Tables 1 to 3 about here}

\subsection{Procedure}

Ethical clearance was granted by the authors' university human research ethics committee and, where required, from organizations who distributed information about the study to parents and clinicians. Two convenience samples were recruited from across Australia: (a) parents of children with UHL identified through newborn hearing screening, 
INFANTS WITH UNILATERAL HEARING LOSS

and (b) clinicians from different disciplines. Information about the study was distributed by email to face-to-face and online parent groups, consumer and professional organizations, and non-government early intervention providers. Parents and clinicians who were interested in participating were emailed more detailed information and a consent form. Verbal consent to participate was confirmed at the time of the interview by the reading of the consent form aloud to each participant. A convenient time for the interview was organized following receipt of a signed consent form. All participants could enter a prize draw to win a $\$ 100$ shopping voucher.

Semi-structured interviews were conducted using a format adapted from tools developed for the Ottawa Decision Support Framework [25]. See Table 4. Parent interviews were conducted by either the first author or an independent research assistant, while the first author conducted all the clinician interviews. Interviews occurred between June 2016 and October 2017. Interviews, which lasted between 30 and 60 minutes, were audio recorded and transcribed, and transcriptions checked for accuracy.

\section{Insert Table 4 about here}

\subsection{Analytic Approach}

Applied Thematic Analysis (ATA) was used to analyse the data [26]. ATA, which integrates other approaches such as grounded theory and phenomenology, is a method for analysing qualitative data for the purpose of representing the experiences of participants. It provides a process for mapping meaningful elements or codes within the data to generate thematic or explanatory models. First, text is segmented based on the interview questions and prompts, and allocated a structural code. Structural codes are the link between data and the content generated in the interviews. The text in each of the structural codes is then coded by content for grouping at specified levels of meaning and interpretation. Content coding 
INFANTS WITH UNILATERAL HEARING LOSS

provides the link between the content and its significance. The same coding process was used for the parent and clinician interviews.

The first author coded all transcripts. Coding for themes was undertaken by the first author in conjunction with the other authors and continued until the final themes were considered to portray the views and experiences of parents and clinicians. Analysis for the purpose of this study focused on three structural codes - information, deliberation, and decision-making process.

\section{Results}

The parent and clinician ${ }^{2}$ interviews provided insight into the complexities surrounding the decision-making process following early identification of UHL. Three main themes captured this process; namely, (1) motivation for decision-making, (2) limited evidence creates uncertainty, and (3) available evidence builds certainty.

\subsection{Motivation for Decision-Making}

The focus for most parents' decision-making was the consideration of an amplification device for their child's affected ear. Their motivation for making these decisions centered around the two sub-themes of (1) parent-centered motivations and (2) child-focused motivations. Both sub-themes had additional sub-themes.

\subsubsection{Parent-centered motivations. The parents' motivations were grounded in their beliefs} and feelings about what would achieve their desired outcomes or goals. Two sub-themes were identified: (1) seeking "normal" and (2) doing something.

3.1.1.1. Seeking "normal". The period following the identification of their infant's hearing loss was often an emotional time for parents. Some parents indicated how their initial response was instinctive and involved seeking solutions that they perceived would make their child "normal" like their normal hearing peers.

\footnotetext{
2 Parent interviewees are identified by the prefix "P" and clinicians by the prefix " $\mathrm{C}$ ".
} 
INFANTS WITH UNILATERAL HEARING LOSS

At the start it was ... because you are so emotional ... your first instinct is to do what you've got to do to make them, it's terrible to say, but as normal as possible ... You always feel like you have to do something to fix them or get them better. (P04) What "normal" might look like varied among parents. For some, this meant hearing with both ears, which necessitated deciding on an amplification device. For others, normal meant no device, because they felt a device would single their child out as different and could result in negative consequences such as bullying. Thus, this sub-theme comprised motivations of some parents to seek solutions that they perceived would provide their child with opportunities to live a normal life, as the parents envisioned it.

3.1.1.2. Doing something. Most parents were motivated by a need to be proactive and to do something to mitigate the potential negative outcomes of UHL for their child. For several parents, whose babies were candidates for an amplification device, choosing a device fulfilled their intrinsic motivation to do something and not wait for problems to occur.

I think even though we don't have any evidence for it, it's like, well, can you do something or not do something? To aid a child, you're actually making a positive step towards doing something for them. Whereas when you're not aiding them, I feel like you're maybe not giving them every opportunity. (P15)

The fact that trialling a hearing aid had no financial implications for families also made it easier for them to do something. Several parents reported that they had two options, namely "a device or nothing." This dichotomous messaging of their options motivated parents to choose a device in order to do something. "They said ... the aid is the only thing ... so we said, 'OK, we'll stick to that then.'” (P03). For some parents whose children had single-sided deafness, the motivation to do something was counterbalanced by decisional conflict and concerns about the consequences of deciding to implant the child: "No, it was quite terrible 
INFANTS WITH UNILATERAL HEARING LOSS

and it was very difficult. Um ... you know, it's major surgery and it's a life-changing thing" (P01).

3.1.2. Child-focused motivations. As parents learned about UHL and the implications for their infant, minimising potential adverse consequences of the hearing loss was at the forefront of their minds. "What is going to benefit her? What will make her life easier?" (P02). Child-focused motivations could be distilled into four sub-themes: (1) two ears are better than one, (2) age-appropriate language, (3) listening and learning, and (4) social and emotional wellbeing.

3.1.2.1. Two ears are better than one. Parents expressed the belief that hearing with two ears was the norm and, therefore, chose a device to optimise their child's access to binaural hearing: "So having access to hearing on both ears really is letting them function how ... you know ... how we were designed to function with ... two ears, two eyes" (P05). Another motivator for seeking solutions to restore bilateral hearing centered on the difficulties imposed by poor lateralisation of sound when only hearing with one ear, and the potential consequences of this on their child's safety on the roads: "I worry about localisation of sound when she's riding a bike ... and ... crossing a road” (P02).

3.1.2.2. Age-appropriate language. Most parents wanted to ensure their child's language followed the same trajectory as their normal hearing peers. Some parents cited this as a reason for their decision to choose a device: “... providing the best opportunity for our child to succeed in her speech and language development" (P15). Some, whose children were not using a device, indicated that they were monitoring the child's speech and language and would review their options if the child started to fall behind their language milestones.

3.1.2.3. Listening and learning. Most parents were motivated by concerns about the effect the child's hearing loss might have on their learning at school. Some had already chosen an amplification device as a way of mitigating adverse effects of UHL at school: 
INFANTS WITH UNILATERAL HEARING LOSS

At school, you know, I didn't want him to come home and say he couldn't hear the teacher, or he couldn't hear whoever because it wasn't loud enough ... I don't want him to get left behind. (P01)

Others, whose child was not currently using a device, noted that the transition to school would be the time they reviewed their available options, if indicated. Most of the parents were aware that remote microphone systems would be beneficial for their child at school, but this did not factor into their early decision-making: "The only thing they said might help him is an FM system when he gets to school” (P06).

3.1.2.4. Social and emotional wellbeing. The child's wellbeing factored into the parents' decision-making: "I just want him to be a happy and confident kid" (P06). They expressed that they wanted the same things for their child as their normal hearing peers - to play sport, have meaningful friendships, and be happy: “It's about them thriving, not just surviving" (P05).

\subsection{Limited Evidence Creates Uncertainty}

The second theme characterized the uncertainty surrounding the decision-making process for both parents and clinicians due to the limited quality evidence for the management of UHL. While decision-making usually involves some uncertainty, parents reported inconsistent recommendations following the identification of their child's hearing loss that increased their uncertainty. This often created polarised opinions. The uncertainty could be categorised into three sub-themes: (1) uncertainty about outcomes, (2) uncertainty about options, and (3) uncertainty about timing of interventions.

3.2.1. Uncertainty about outcomes. Outcome uncertainty was problematic for a number of the participating clinicians:

It's hard because [parents] just want to know if everything is going to be, you know, normal ... and, I guess, research-wise it's really hard to say exactly what kind of 
INFANTS WITH UNILATERAL HEARING LOSS

outcomes they're going to ... like there's no kind of conclusive research to say they're going to have $X, Y$, and $Z$ problems $(\mathrm{C} 12)$.

This was felt more acutely by the audiologists assisting families to make decisions about devices: "If there was concrete research to say either way ... what was a better option ... which was not ... 'cos I know outcomes are so variable. I don't feel like I have any answers for parents ... with a child with unilateral hearing loss" (C09).

3.2.2. Uncertainty about options. There were substantial differences in the options for the management of UHL suggested to parents, from regular monitoring of the child's hearing to similar interventions as children with bilateral hearing loss. All clinicians noted the importance of children with UHL having their hearing regularly checked, but they demonstrated conflicting opinions over whether these children required further intervention and what that intervention might be. Some clinicians were cognisant of the disparate advice and opinions being provided to parents and the difficulty this can pose for parents trying to make decisions: "We don't really have a clear recommendation for them, so we probably put a lot back on them and probably expect them to make a whole lot of sense out of information that probably wouldn't make much sense to them" (C09).

Several clinicians favoured a management approach that included active monitoring of hearing and child development along with comprehensive parent education. However, while recognising parents needed to be made aware of all their options, they were ambivalent about routine device fitting for children with UHL, worrying that the disadvantages might outweigh the advantages for many due to the uncertainty about predicting which children might need additional support. Clinician 14 noted “... for a lot of kids with unilateral hearing loss, intervening turns something into a disability which wasn't going to be a disability". 
INFANTS WITH UNILATERAL HEARING LOSS

Uncertainty about their options was complicated by parental understanding that they had only two options, namely "a device or nothing". This dichotomous messaging reported by parents about their options was confirmed by a number of the clinicians who consistently indicated that "I think, doing nothing, really means 'don't aid"” (C05). Despite clinicians being proponents for active surveillance and/or early childhood intervention, this binary messaging prompted parents to believe that, even if their child's hearing and speech were actively monitored, they were "doing nothing" to manage the hearing loss. "I mean ... to be honest ... to be brutally honest, there has been no management plan ... Basically just to wait and see ... come back ... and hearing checks of the ear, or both ears, every six to twelve months" (P10).

Most parents supported the notion that "two ears are better than one" and uncertainty, therefore, persisted for parents whose specialist advised against the use of a device. These parents tended to do their own research on possible technological solutions for their child's hearing loss. For some parents, conflicting information from different professionals and the lack of consensus regarding the need for amplification devices in children with UHL resulted in their questioning of professional recommendations and uncertainty about whom they could trust: “... it would have helped us have more of a consensus from professionals” (P07).

For parents who delayed making a decision about a device at the time of diagnosis, their uncertainty about the need for a device shifted over time. Some parents indicated that the longer they waited to decide on a device, the less inclined they were to choose one in the face of evidence that the child was progressing well without it. Despite this, they also acknowledged ongoing uncertainty and recognised that they might need to revisit their decision if the child experienced difficulties at school. "Sometimes I still waiver. I don't think you can be completely confident one way or the other (P07)." 
INFANTS WITH UNILATERAL HEARING LOSS

3.2.3. Uncertainty about timing of interventions. Some clinicians believed that if a non-invasive device (hearing aid or softband bone conduction device) was an option for the child, then it should be actively encouraged from the time of identification. "If amplification is indicated, then I think it should be tried ... robustly" (C01). They indicated that there was no evidence to suggest that these devices could cause harm to the child and were, therefore, worth fitting immediately upon diagnosis. Other clinicians, however, were less certain about fitting a device early when "... there is no way of knowing which children are going to have those difficulties later and those who manage well with other strategies” (C08).

For parents considering an implant for their child, the tension around timing was evident. Knowing that deferring the decision would mean that a cochlear implant was less likely to be beneficial, presented an additional burden to the decision-making process. One family felt pressured to implant their child early: ... at times we felt a bit pushed by them for it ... but we took a step back” (P01). They were, however, ultimately persuaded to act early and then let the child choose whether to wear the implant or not when older. However, this timing pressure was not consistent across families, with another family feeling comfortable to defer the decision to implant: "We kind of have the theory that if he wants something to be done, he can decide when he is old enough" (P04).

\subsection{Available evidence builds certainty}

While the limited evidence available created uncertainty for some, there were two sources of information that provided clarity and certainty for many parents; namely, (a) expert advice and (b) lived experience.

3.3.1. Expert advice. Parents relied heavily on the advice and opinions of their medical specialists, particularly their ear, nose, and throat specialist (ENT), who they consulted after their diagnostic appointment: "I really relied on our ENT specialist" (P12). The expert advice provided to parents about intervention for UHL fell broadly into two 
INFANTS WITH UNILATERAL HEARING LOSS

philosophies - (a) "two ears are better than one": "[ENT] confirmed it and said, "This is your option. You need to go to [hearing service provider] now. He is going to need an aid.' And that's pretty much it" (P03), and (b) "one good ear is fine": “We were basically told ... he's got one ear with perfect hearing, so he'll be fine. You only need one good ear for ... you know ... learning and development” (P06).

The parents generally appeared to follow the management advice outlined by their specialist consultant. The participating audiologists discussed how they attempted to provide parents with balanced information about their options, but this could be challenging when parents had already decided on what they wanted before arriving for the appointment. "A lot of the time they'll come with a referral from the ENT saying they need the hearing aid ... So they've already got that idea in their minds" (C09).

Other clinicians, such as early intervention providers and those in the newborn hearing screening team, were an additional source of information and advice that helped to reassure some parents that they were doing the right thing. For example, the social worker at the hospital had been a reassuring sounding board for one family's decision-making: "She's certainly not necessarily given us advice, but just reassured us that our thought process or our research process has been a sound one and that we seem to be making sound decisions, so that was helpful” (P11).

The written information given to parents was focused largely on bilateral hearing loss: "It was a booklet just explaining ... you know ... explaining hearing loss more broadly" (P05). However, some parents felt the information regarding early amplification for children with bilateral loss was sufficient for them to choose a device for use with their child who had UHL. "The research for bilateral hearing loss tells us that the earlier you start, the better. So, we figured that maybe it would be the same" (P15). 
INFANTS WITH UNILATERAL HEARING LOSS

3.3.2. Lived experience. Opinions and advice from people with lived experience of UHL were influential for some. Most parents did their own research using the Internet and all participated in at least one online support group. The experiences of other parents or adults with UHL gave parents some confidence to make a decision. Some were persuaded to aid their child as a result: "After I did a lot of reading on these groups, and I saw how many people aided ... it was pretty obvious to me this is what we have to do" (P14). Others were less inclined to opt for amplification after learning of the experiences of adults who had never used a device: “I've spoken to adults that have [UHL] ... some people ... haven't developed as well as they should ... but 90 percent [developed] normally” (P10).

\section{Discussion}

We examined the decision-making process of parents following the identification of their infant's UHL by exploring their experiences and the practices of the clinicians they consulted. We found the motivations for parental decision-making had two underpinnings the need of the parents to do something to normalise the situation, and consideration of the future needs of their child. The principal option the parents explored for the management of their child's UHL was device fitting. The decisions they made to achieve their desired outcomes were shaped by the limited and variable information available, and the advice and recommendations received from specialists, clinicians, and people with the lived experience of UHL. The findings highlight the differing approaches to making decisions when there is no clear "best" option and the potential for parent and clinician biases to influence parental decision-making.

Parents and clinicians bring different knowledge and motivations to the decisionmaking process [27]. Clinicians are charged with helping parents make informed decisions, preferably through a process of shared decision-making where they share the best available evidence and support the family's consideration of their preferences in order to reach a 
INFANTS WITH UNILATERAL HEARING LOSS

decision that is "emotionally responsive to the situation, feasible and desirable to implement, and has an intellectually sound logic or argument" [28]. The audiologists in our study reported that they found assisting families to make informed decisions more challenging in the case of UHL than bilateral hearing loss. The uncertainty of knowing if UHL might have adverse consequences for a particular child led to some discomfort about recommending a device. Supporting parents through a process of informed decision-making, particularly when parents came to their appointment with clear recommendations from their medical specialists for or against device-fitting, was challenging for many of the audiologists.

The opinions of medical specialists and other clinicians carried great weight for parents. Recommendations from an authoritative or powerful person can shape or nudge choices as a result of the messenger effect, where the person delivering the advice influences the decision rather than the content of the advice [29]. The interviews indicated a dichotomous approach taken by medical specialists and clinicians to the management of UHL in infants, where parents were either recommended a device or were told a device was not necessary or possible. In situations where there is limited evidence for optimal intervention and treatment options, some health professionals believe their clinical experience provides sufficient evidence to support one option over another [30]. In this scenario, many believe there is ethical justification for nudging people to make choices that are in their best interest $[29,31]$. Some argue that nudging, that is, "any influence that is expected to predictably alter a person's behaviour without explicitly forbidding options or substantively changing the target's reasons for acting" (p.536) [32] is a legitimate practice to improve the decisionmaker's own welfare [33]. Nudge tools or techniques use cognitive biases and heuristics such as the messenger effect, framing effect, and social norms to influence decision-making. Blumenthal-Barby and Opel [29] have argued that there is strong ethical justification for nudging in parental decision-making as parents are not always able to separate their own 
INFANTS WITH UNILATERAL HEARING LOSS

needs and motivations from the best interests of the child, especially when the decision is one that is outside the parents' typical sphere of understanding. They did, however, argue that in situations where "the risks, benefits, or uncertainty become equivocal, use of nudges is more questionable" (p. 37). Others have argued that nudging is inconsistent with genuine informed consent $[31,32]$. The way the parents reported the information about the options offered by specialists and clinicians suggests that they might have been nudged, either intentionally or inadvertently, towards the preferred option of the specialist or clinician. This raises questions about whether this is consistent with genuine informed choice [29, 31].

The identification of hearing loss in their infant was a completely unexpected event for the parents in our sample, as is the case for $90 \%$ of parents whose babies are identified with hearing loss [34]. Parents wanted to be proactive and not wait for potential adverse outcomes to occur, and this intrinsic motivation to do something often involved deciding on the fitting of a device. The newborn screening process sits within a health system that primarily applies a medical lens on the diagnosis of deafness. Deafness is seen as a disability that needs treatment, and amplification devices, such as hearing aids and cochlear implants, are promoted as an optimal solution to "fix" the problem [35-37]. The medical focus of newborn hearing screening directs attention on what the child cannot do [38] (i.e., cannot hear with one ear) and parents sought to fix this problem by providing their infant with hearing in the affected ear. The apparent promise of technological solutions enabled parents to meet their need to be proactive and do something to fix the problem. Adding to their belief about the superiority of a device was how the parents "perceived" the options offered to them [23]. Some parents reported that they were told that their options were a device or nothing. We do not know exactly how the information provided to parents was framed, but they nonetheless interpreted the information as meaning that if they did not choose a device, or 
INFANTS WITH UNILATERAL HEARING LOSS

were not offered a device, they were not doing enough to help their infant, which was contrary to their needs and motivations.

Research into the framing effect in medical decision-making has demonstrated that people make different decisions depending on how the information is framed or presented [39]. Framing of information in a loss or gain perspective has been repeatedly shown to influence people's decision-making. Blumenthal-Barby and Opel [29] used a scenario of a hypothetical angioplasty to determine the effect of loss and gain messaging on people's decision-making, finding that $49 \%$ of patients refused the hypothetical treatment when information was presented in a loss frame (i.e., that 1 in 100 patients have complications) compared to only $15 \%$ who received the gain-framed information (i.e., that 99 in 100 people had no complications). While people are less likely to choose loss-framed options, these also are more persuasive in behaviours that result in uncertain outcomes [40], such as exists with UHL. Parents in the current study focused their decision-making on minimising any potential adverse outcomes such a language delays and academic performance (disability/loss perspective) rather than greater likelihood of similar outcomes as their normal hearing peers [1] (gain perspective). Further investigation is needed to explore the framing of information provided to parents and the effect that this has on their decision-making.

Unfortunately, simply alerting people to be aware of a particular bias has little effect as biases are largely not conscious [41]. Emerging research is investigating de-biasing strategies that are showing promise, including the use of patient decision aids [42] and decision justification methods [39], but these require further development and investigation. What is evident, however, is that providing parents with critically evaluated and balanced information about their options, and helping them to understand the positive and negative consequences of choosing each one, is likely to result in more informed decisions [10, 20, 39, 43]. 
INFANTS WITH UNILATERAL HEARING LOSS

Hussain et al. [23] described the iterative approach to decision-making taken by parents as they observed their child's progress (children aged 4 months to 16 years) and considered their options. Many of the families in our study whose babies were assessed as having aidable hearing were fitted with hearing aids or bone conduction devices from the outset, and the child's subsequent progress was observed through the lens of their decision to fit a device. However, for the few families whose child was not provided a device, a more iterative process was evident. Some reported moving increasingly away from choosing a device as they observed that their child was developing like their normal hearing peers, while others reported exploring new and different devices in their ongoing search for technological solutions. Similar to Hussain et al.'s study, parents in our study viewed "normal" according to the decision they had made, either with or without a device.

Rather than relying solely on clinicians for information and advice, parents frequently turned to online support groups for information about the lived experience of other parents of children with UHL or adults with the condition. Hearing other peoples' experiences provided a different perspective for parents and affected the decisions of several. All parents belonged to at least one Facebook group about UHL. These groups provided information and emotional support and were a regular feature of the parent experience following the diagnosis of their infant's UHL. Online information about what other people are doing can help parents understand their options and alternatives, but caution is needed [44]. The personalised algorithmic filters used by sources such as Facebook and Google can bias user's thinking [45], so are particularly problematic when quality and unbiased information is needed. Feeds are likely to point parents towards views they already hold, and it can be difficult to distinguish quality information from promotional material $[36,46]$. The availability heuristic, where recent experiences can dominate thinking and deciding, can convince group members that certain options or outcomes are more prevalent than evidence indicates. Online groups 
INFANTS WITH UNILATERAL HEARING LOSS

bring people with particular interests together and can become an environment for

confirmatory opinions that limit the exploration of other options, potentially leading to poor decisions for the unwary member $[44,46]$. Further investigation into strategies that can assist parents to enjoy the benefits of online peer support while recognising the possibility that their thinking and deciding might be adversely influenced in online groups is needed.

\subsection{Limitations}

Parents were interviewed when their children were still young. Some parents had made major decisions regarding the management of their child's hearing loss prior to the interview, particularly those parents who had chosen to implant their child, and the outcomes of their decisions were not yet apparent. The interviewers were cognisant of needing to respect the parent's decision and not challenge what they knew about the consequences of choosing an option prior to implementation. This meant that, in some cases, we were unable to explore their knowledge and values in depth.

In qualitative research, the epistemological perspective, personal identity, and experiences of the interviewer and/or the researchers can shape the questions that are asked, the framing of the questions, and the analysis of the data [38]. In this study, one interviewer, the first author, is a parent advocate and mentor whose child has single side deafness and was known to some of the parents and clinicians. This dual-role tension is not uncommon with clinician/expert-as-researcher and there are some advantages to this, as knowledge of the lived experience of the interviewer enables parents to be more open and candid in their responses [47]. However, recognising the potential bias, a second experienced but independent (i.e., no connection with deafness) interviewer was also used. Scrutiny of interview transcripts from both interviewers revealed a coherence and little evidence of impact on the themes. 
INFANTS WITH UNILATERAL HEARING LOSS

All participants were English-speaking Australians and all but one parent, were female; thus, generalizability is restricted. Given the difficulty that these English-speaking parents had in finding and understanding information, it is likely that migrant families with limited host language proficiency would experience more challenges, further limiting their ability to make informed decisions. Understanding the views, experiences and needs of parents that reflect the diversity within the population is an important avenue for future research regarding parental decision-making.

Finally, the diversity of clinicians who participated was limited. Given the importance of the medical professionals' opinions and advice in parental decision-making, it would have been beneficial to have representation of paediatricians and ENTs in the study.

\section{Conclusion}

The potential adverse consequences of UHL are not insignificant for many children. Equally, many of the choices that parents make at the time of identification of their child's UHL are not insignificant and could have lifelong implications for their child. Many questions need to be answered before parents can effectively evaluate the short- and longterm consequences of their options and decide whether the benefits of an option outweigh the risks in the long-term. Current research focuses almost exclusively on the use of devices for UHL, with little consideration of the benefits and risk of adopting adaptive strategies. In Australia, management for children with congenital hearing loss has swung from viewing the child with UHL as an essentially hearing child requiring minimal intervention to regarding them as essentially deaf and needing similar interventions to children with bilateral hearing loss. Further research is needed to evaluate the full range of options so that parents are appropriately informed and can decide on the best option for their situation.

\section{Acknowledgements}


INFANTS WITH UNILATERAL HEARING LOSS

Our warm thanks to the parents and clinicians who participated in the interviews. Thank you to research assistants Matthew McKenzie and Jessica Arentz.

\section{Funding}

This research did not receive any specific grant from funding agencies in the public, commercial, or not-for-profit sectors. 
INFANTS WITH UNILATERAL HEARING LOSS

References

[1] L.A. Krishnan, S. Van Hyfte, Management of unilateral hearing loss, Int. J. Pediatr. Otorhinolaryngol. 88 (2016) 63-73, https://doi.org/10.1016/j.ijporl.2016.06.048.

[2] F.H. Bess, A.M. Tharpe, Case history data on unilaterally hearing-impaired children, Ear Hear. 7 (1986) 14-19, https://doi.org/10.1097/00003446-198602000-00004.

[3] K. Huttunen, E. Erixon, U. Lofkvist, E. Maki-Torkko, The impact of permanent earlyonset unilateral hearing impairment in children - A systematic review, Int. J. Pediatr. Otorhinolaryngol. 120 (2019) 173-183, https://doi.org/10.1016/j.ijporl.2019.02.029.

[4] S. Appachi, J.L. Specht, N. Raol, et al., Auditory outcomes with hearing rehabilitation in children with unilateral hearing loss: A systematic review, Otolaryngol. Head Neck Surg. 157 (2017) 565-571, https://doi.org/10.1177/0194599817726757.

[5] S. Anne, J.E.C. Lieu, M.S. Cohen, Speech and language consequences of unilateral hearing loss: A systematic review, Otolaryngol. Head Neck Surg. 157 (2017) 572579, https://doi.org/10.1177/0194599817726326.

[6] C.C. Liu, D. Livingstone, W.K. Yunker, The role of bone conduction hearing aids in congenital unilateral hearing loss: A systematic review, Int. J. Pediatr.

Otorhinolaryngol. 94 (2017) 45-51, https://doi.org/10.1016/j.ijporl.2017.01.003.

[7] J.P. Peters, G.G. Ramakers, A.L. Smit, W. Grolman, Cochlear implantation in children with unilateral hearing loss: A systematic review, Laryngoscope. 126 (2016) 713-721, https://doi.org/10.1002/lary.25568.

[8] P.L. Purcell, J.R. Shinn, G.E. Davis, K.C. Sie, Children with unilateral hearing loss may have lower intelligence quotient scores: A meta-analysis, Laryngoscope. 126 (2016) 746-754, https://doi.org/10.1002/lary.25524. 
INFANTS WITH UNILATERAL HEARING LOSS

[9] A. Porter, P. Creed, M. Hood, T.Y.C. Ching, Parental decision-making and deaf children: a systematic literature review, J. Deaf Stud. Deaf Educ. 23 (2018) 295-306, https://doi.org/10.1093/deafed/eny019.

[10] M. Bagatto, J. DesGeorges, A. King, et al., Consensus practice parameter: audiological assessment and management of unilateral hearing loss in children, Int. J. Audiol. 58 (2019) 1-11, https://doi.org/10.1080/14992027.2019.1654620.

[11] T. Ching, Unilateral hearing loss: What's known,...and lacking. https://cuhl.nal.gov.au/papers.html, 2014 (accessed 6 January 2021).

[12] Department of Health, National Framework for Neonatal Hearing Screening. https://www1.health.gov.au/internet/main/publishing.nsf/Content/neonatal-hearingscreening, 2013 (accessed 6 January 2021).

[13] L. Buckmaster, S. Clark. The National Disability Insurance Scheme: A chronology. Research Paper Series, 2018-19. 2018.

https://parlinfo.aph.gov.au/parlInfo/download/library/prspub/6083264/upload binary/ 6083264.pdf, 2018 (accessed 6 January 2021).

[14] D.L. Sackett, W.M.C. Rosenberg, The need for evidence-based medicine, J. R.Soc. Med. 88 (1995) 620-624, https:// doi.org/10.1093/oxfordjournals.pubmed.a043127.

[15] A. Paton, N. Armstrong, L. Smith, R. Lotto, Parents' decision-making following diagnosis of a severe congenital anomaly in pregnancy: Practical, theoretical and ethical tensions, Soc Sci Med. 266 (2020) 113362-113362, https://doi.org/10.1016/j.socscimed.2020.113362.

[16] G. Elwyn, D. Frosch, S. Rollnick, Dual equipoise shared decision making: Definitions for decision and behaviour support interventions, Implement. Sci. 4 (2009) 75, https://doi.org/10.1186/1748-5908-4-75. 
INFANTS WITH UNILATERAL HEARING LOSS

[17] T.C. Hoffman, F. Legare, M.B. Simmons, et al., Shared decision making: What do clinicians need to know and why should they bother? Med. J. Aust. 201 (2014) 35-39, https://doi.org/10.5694/mja14.00002

[18] A. Kon, The shared decision-making continuum, JAMA. 304 (2010) 903-904, https://doi.org/10.1001/jama.2010.120.

[19] S. M. L. de Mik, F. E. Stubenrouch, R. Balm, D. T. Ubbink, Development of three different decision support tools to support shared decision-making in vascular surgery, Patient Educ. Couns. 104 (2021) 282-289, https://doi.org/10.1016/j.pec.2020.11.036.

[20] P. Abhyankar, R.J. Volk, J. Blumenthal-Barby, et al., Balancing the presentation of information and options in patient decision aids: an updated review, BMC Medical Inform. Decis. Mak. 13 (Suppl 2) (2013) S6, https://doi.org/10.1186/1472-6947-13$\underline{\text { S2-S6. }}$

[21] M.E. Graham, R. Haworth, J. Chorney, M. Bance, P. Hong, Decisional conflict in parents considering bone-anchored hearing devices in children with unilateral aural atresia, Ann. Otol. Rhinol. Laryngol. 124 (2015) 925-930, https://doi.org/10.1177/0003489415592000.

[22] E. Fitzpatrick, V. Grandpierre, A. Durieux-Smith, I. Gaboury, D. Coyle, E. Na, N Sallam, Children with mild bilateral and unilateral hearing loss: Parents' reflections on experiences and outcomes, J. Deaf Stud. Deaf Educ. 21 (2016) 34-43, https://doi.org/10.1093/deafed/env047.

[23] S. Hussain, H. Pryce, A. Neary, A. Hall, Exploring how parents of children with unilateral hearing loss make habilitation decisions: a qualitative study, Int. J. Audiol. 60 (2020) 183-190, https://doi.org/10.1080/14992027.2020.1804080. 
INFANTS WITH UNILATERAL HEARING LOSS

[24] E. Fitzpatrick, C. Roberts, J. Whittingham, C. Barreira-Nielsen, Amplification decisions for children with mild bilateral and unilateral hearing loss, CJSLPA. 41 (2017) 203-226.

[25] M.J. Jacobsen, A.M. O’Connor, D. Stacey, Decisional needs assessment in populations: A workbook for assessing patients' and practitioners' decision making needs. https://decisionaid.ohri.ca/docs/implement/population_needs.pdf, 2013 (accessed 6 January 2021).

[26] G. Guest, K.M. MacQueen, E.E. Namey, Introduction to applied thematic analysis in: Applied Thematic Analysis, SAGE, Thousand Oaks, 2012, pp. 3-21.

[27] M.P. Moeller, G. Carr, L. Seaver, A. Stredler Brown, D. Holzinger, Best practices in family centered early intervention for children who are deaf or hard of hearing: An international consensus statement, J. Deaf Stud. Deaf Educ. 18 (2013) 429-445, https:// doi.org/10.1093/deafed/ent034.

[28] I.G. Hargraves, A.K. Fournier, V.M. Montori, A.S. Bierman, Generalized shared decision making approaches and patient problems. Adapting AHRQ's SHARE approach for purposeful SDM, Patient Educ. Couns. 103 (2020) 2192-2199, https://doi.org/10.1016/j.pec.2020.06.022.

[29] J. Blumenthal-Barby, D.J. Opel, Nudge or grudge? Choice architecture and parental decision-making, Hastings Cent. Rep. 48 (2018) 33-39, https://doi.org/10.1002/hast.837.

[30] C. Cook, C. Sheets, Clinical equipoise and personal equipoise: two necessary ingredients for reducing bias in manual therapy trials, J. Man. Manip. Ther. 19 (2011) 55-57, https://doi.org/10.1179/106698111X12899036752014. 
INFANTS WITH UNILATERAL HEARING LOSS

[31] Ploug, S. Holm, Doctors, patients, and nudging in the clinical context-four views on nudging and informed consent, Am. J. Bioeth. 15 (2015) 28-38, https://doi.org/10.1080/15265161.2015.1074303.

[32] W. Simkulet, Nudging, informed consent and bullshit, J. Med. Ethics. 44 (2018) 536542. https://doi.org/10.1136/medethics-2017-104480

[33] J.S. Blumenthal-Barby, On nudging and informed consent-four key undefended premises, Am. J. Bioeth. 13 (2013) 31-33. https://doi.org/10.1080/15265161.2013.781717.

[34] R.E. Mitchell, M.A. Karchmer, Chasing the mythical ten percent: Parental hearing status of deaf and hard of hearing students in the United States, Sign Lang. Stud. 4 (2004) 138-163, https:// doi.org/10.1353/sls.2004.0005.

[35] C. Harris, S. Hemer, A. Chur-Hansen, Emotion as motivator: Parents, professionals and diagnosing childhood deafness, Med. Anthropol. (2020), https:// doi.org/10.1080/01459740.2020.1796659.

[36] E. Kecman, Old challenges, changing contexts: reviewing and reflecting on information provision for parents of children who are deaf or hard-of-hearing, Deafness Educ. Int. 21 (2019) 3-24, https://doi.org/10.1080/14643154.2018.1506072.

[37] L. Mauldin, Don't look at it as a miracle cure: Contested notions of success and failure in family narratives of pediatric cochlear implantation, Soc. Sci. Med. 228 (2019) 117-125, https:// doi.org/10.1016/j.socscimed.2019.03.021.

[38] A. Young, T. Bogusia, Approaches to social research: The case of deaf studies, Oxford University Press, Oxford, UK, 2014.

[39] S. Almashat, B. Ayotte, B. Edelstein, J. Margrett, Framing effect debiasing in medical decision making, Patient Educ Couns. 71 (2008) 102-107, https://doi.org/10.1016/j.pec.2007.11.004. 
INFANTS WITH UNILATERAL HEARING LOSS

[40] B.A. Toll, S.S. O'Malley, N.A. Katulak, et al., Comparing gain- and loss-framed messages for smoking cessation with sustained-release bupropion: A randomized controlled trial, Psychol. Addict. Behav. 21 (2007) 534-544, https:// doi.org/10.1037/0893-164X.21.4.534.

[41] S.G. Campbell, P. Croskerry, D.A. Petrie, Cognitive bias in health leaders, Healthc. Manage. Forum. 30 (2017) 257-261, https://doi.org/10.1177/0840470417716949.

[42] R. Ludolph, P.J. Schulz, Debiasing health-related judgments and decision making: A systematic review, Med. Decis. Making. 38 (2017) 3-13, https://doi.org/10.1177/0272989X17716672.

[43] J. Baron, Thinking and deciding, 4th ed., Cambridge University Press, New York, USA, 2008.

[44] S.U.E. Ziebland, S. Wyke, Health and illness in a connected world: How might sharing experiences on the internet affect people's health?, Milbank Q. 90 (2012) 219249, https:// doi.org/10.1111/j.1468-0009.2012.00662.x.

[45] E. Bozdag, Bias in algorithmic filtering and personalization, Ethics Inf. Technol. 15 (2013) 209-227, https:// doi.org/10.1007/s10676-013-9321-6.

[46] G. Petrič, S. Atanasova, T. Kamin, Ill literates or illiterates? Investigating the ehealth literacy of users of online health communities, J. Medical Internet Res. 19 (2017) e331, https:// doi.org/10.2196/jmir.7372.

[47] E.J.C. Hay-Smith, M. Brown, L. Anderson, G.J. Treharne, Once a clinician, always a clinician: a systematic review to develop a typology of clinician-researcher dual-role experiences in health research with patient-participants, BMC Medical Res. Methodol. 16 (2016) 95, https:// doi.org/10.1186/s12874-016-0203-6. 
INFANTS WITH UNILATERAL HEARING LOSS

[48] Australian Bureau of Statistics, Socio-economic indexes for Australia (SEIFA), 2016. https://www.abs.gov.au/AUSSTATS/abs@.nsf/DetailsPage/2033.0.55.0012016?Open Document, 2018 (accessed 6 January 2021). 
INFANTS WITH UNILATERAL HEARING LOSS

Table 1

Parent Demographics

\begin{tabular}{lrr}
\hline & $\mathrm{N}$ & $\%$ \\
\hline Relationship to child & & \\
Mother & 14 & 93.3 \\
Father & 1 & 6.7 \\
Age & 4 & 26.7 \\
$21-30$ & 10 & 66.7 \\
$31-40$ & 1 & 6.7 \\
$41-50$ & & \\
Level of education & 5 & 33.3 \\
$\quad$ High school & 5 & 33.3 \\
$\quad$ Vocational training & 1 & 6.7 \\
Undergraduate & 4 & 26.7 \\
Postgraduate & & \\
Employment status & 1 & 6.7 \\
Homemaker & 2 & 13.3 \\
Maternity leave & 7 & 46.7 \\
Part-time & 5 & 33.3 \\
Full-time & & \\
IRSD & 3 & 20.0 \\
Scores 1-3 (Relative disadvantage) & 4 & 27.0 \\
Scores 4-6 & 8 & 53.0 \\
Scores 7-10 (Relative lack of disadvantage) & &
\end{tabular}

${ }^{a}$ The Index of Relative Socio-economic Disadvantage (IRSD) summarises information about economic and social conditions of households in each postcode in Australia [48]. 
INFANTS WITH UNILATERAL HEARING LOSS

Table 2

\section{Child Characteristics}

\begin{tabular}{lrr}
\hline & $\mathrm{N}$ & \multicolumn{1}{c}{$\%$} \\
\hline Gender & & \\
Female & 8 & 53.3 \\
Male & 7 & 46.7 \\
Age (months) & & \\
$0-6$ & 2 & 13.3 \\
$7-12$ & 2 & 13.3 \\
13-24 & 0 & 0.0 \\
$25-30$ & 8 & 53.3 \\
$31-36$ & 2 & 13.3 \\
37-42 & 0 & 0.0 \\
43-48 & 1 & 6.7 \\
Type of hearing loss & & \\
Sensorineural & 14 & 93.3 \\
Conductive & 1 & 6.7 \\
Severity of hearing loss & & \\
Profound & 7 & 46.7 \\
Severe-profound & 2 & 13.3 \\
Severe & 1 & 6.7 \\
Moderate-severe & 3 & 20.0 \\
Mild-moderate & 1 & 6.7 \\
Unknown & 1 & 6.7 \\
Side of hearing loss & & \\
Left & 8 & 53.3 \\
Right & 6 & 40.0 \\
Unknown & 1 & 6.7 \\
Cause of hearing loss & &
\end{tabular}

Cause of hearing loss

Cytomegalovirus

$3 \quad 20.0$

$\begin{array}{lll}\text { Thin or absent cochlear nerve } & 3 & 20.0\end{array}$

$\begin{array}{lll}\text { Microtia and atresia } & 1 & 6.7\end{array}$

Unknown $\quad 8 \quad 53.3$

Additional conditions

$\begin{array}{lll}\text { Otitis media } & 2 & 13.3\end{array}$

Auditory Neuropathy Spectrum Disorder $\quad 1 \quad 6.7$

$\begin{array}{lll}\text { Hip dysplasia } & 1 & 6.7\end{array}$

Absent kidney $\quad 1 \quad 6.7$

$\begin{array}{lll}\text { None or unknown } & 10 & 66.7\end{array}$

Type of device

No device

$4 \quad 33.3$

$\begin{array}{lll}\text { Hearing aid } & 5 & 33.3\end{array}$

Bone conduction device $\quad 3 \quad 13.3$

$\begin{array}{lll}\text { Cochlear implant } & 2 & 13.3\end{array}$

$\begin{array}{lll}\text { Cochlear implant evaluation } & 1 & 6.7\end{array}$

Note. Child characteristics as reported by the parent interviewee. 
INFANTS WITH UNILATERAL HEARING LOSS

Table 3

Clinician Demographics

\begin{tabular}{|c|c|c|}
\hline & $\mathrm{N}$ & $\%$ \\
\hline \multicolumn{3}{|l|}{ Gender } \\
\hline Female & 14 & 100 \\
\hline Male & 0 & 0 \\
\hline \multicolumn{3}{|l|}{ Age (years) } \\
\hline $20-29$ & 3 & 21.4 \\
\hline $30-39$ & 3 & 21.4 \\
\hline $40-49$ & 3 & 21.4 \\
\hline $50-59$ & 2 & 14.3 \\
\hline$>60$ & 3 & 21.4 \\
\hline \multicolumn{3}{|l|}{ Area of expertise } \\
\hline Audiology & 3 & 21.4 \\
\hline Audiology (cochlear implant) & 2 & 14.3 \\
\hline Diagnostic audiology & 3 & 21.4 \\
\hline Psychologist & 2 & 14.3 \\
\hline Social worker & 1 & 7.1 \\
\hline Speech pathologist & 1 & 7.1 \\
\hline Teacher of the Deaf & 2 & 14.3 \\
\hline \multicolumn{3}{|l|}{ Years of experience } \\
\hline$<5$ & 6 & 42.9 \\
\hline $6-10$ & 2 & 14.3 \\
\hline $11-20$ & 1 & 7.1 \\
\hline $21-30$ & 1 & 7.1 \\
\hline$>30$ & 4 & 28.6 \\
\hline \multicolumn{3}{|l|}{ State } \\
\hline NSW & 6 & 42.9 \\
\hline QLD & 4 & 28.6 \\
\hline SA & 1 & 7.1 \\
\hline VIC & 1 & 7.1 \\
\hline WA & 2 & 14.3 \\
\hline \multicolumn{3}{|l|}{ Location } \\
\hline Metropolitan & 9 & 64.3 \\
\hline Mixed (metro, regional \& rural) & 5 & 35.7 \\
\hline
\end{tabular}


INFANTS WITH UNILATERAL HEARING LOSS

Table 4

Interview Guide Examples - Parents and Clinicians

Parent interview examples
- Since [child's name] diagnosis, what decisions have you needed to make with regards to the hearing loss?

- How do you usually go about making these decisions?

- Thinking about this decision, what are the options you have/had?

- What do you see as the main advantages and disadvantages of the options?

- What would/would have help[ed] you make this decision?

- What things made/are making this decision difficult to make?

- Is there anything else that would/would have help[ed] you when making this decision?
Clinician interview examples

- What are the decisions that you think parents need to make in the early days?

- Can you discuss how you go about assisting families to make the decisions that they need to make?

- What do you see as the main options regarding the management of unilateral hearing loss in babies and young children?

- What do you see as the main benefits/advantages and risks/disadvantages of these options?

- What are the factors that make it difficult for you to support parents in their decisionmaking?

- What are the particular barriers for parents whose children have UHL rather than bilateral loss?

- Is there anything else that would help you to support parents in their decision-making? 


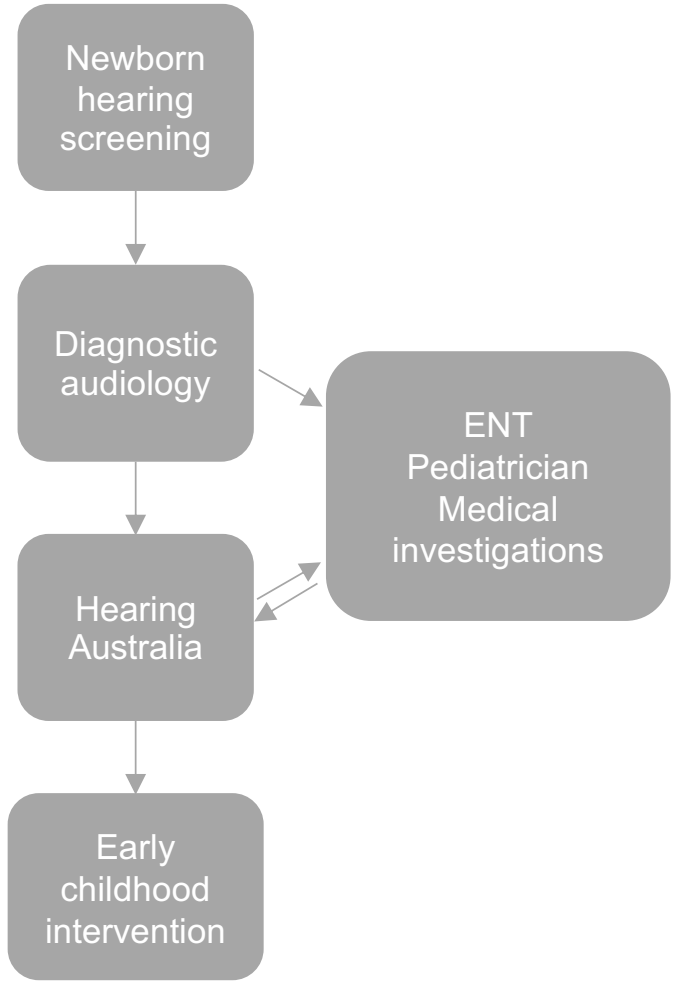

Figure 1. Typical newborn hearing screening pathway across Australia. 